\title{
Accuracy of Fine Needle Cytology in Histological Prediction of Papillary Thyroid Carcinoma Variants: a Prospective Study
}

\author{
Anna Cipolletta Campanile ${ }^{1}$ Maria Gabriella Malzone ${ }^{1} \cdot$ Nunzia Simona Losito $^{1}$. \\ Gerardo Botti $^{1}$ - Maria Grazia Chiofalo ${ }^{2}$. Antongiulio Faggiano ${ }^{2} \cdot$ Roberta Siciliano $^{3}$. \\ Annamaria Colao ${ }^{4} \cdot$ Luciano Pezzullo $^{2} \cdot$ Franco Fulciniti $^{5}$
}

Published online: 21 June 2017

(C) Springer Science+Business Media, LLC 2017

\begin{abstract}
Fine needle cytology (FNC) is a crucial procedure in the preoperative diagnosis of thyroid tumors. Papillary thyroid carcinoma (PTC), in its classic variant (cPTC), is the most common malignant neoplasm of the thyroid. Several histological variants of PTC have been described, each one with its own characteristics and prognosis. The ability of FNC to identify the variants represents a challenge even for a skilled pathologist. The aim of this study was to evaluate the diagnostic cytological accuracy of FNC in PTC and to look for specific features that could predict the different variants. This was a single center prospective study on 128 patients who received a diagnosis of PTC on FNC. The smears were blindly reviewed by two cytopathologists to create a frequency score $(0,1,2,3)$ of the features for each variant. The cytological parameters were divided into three groups: architectural, nucleo-cytoplasmic, and background features. Univariate analysis was performed by chi-square test with Yates correction and Fisher exact test as appropriate. Multiple regression analysis was performed among the variables correlated at the linear
\end{abstract}

Maria Gabriella Malzone

gabriellamalzone@hotmail.com

1 Pathology and Cytopathology Unit, National Cancer Institute "Fondazione G. Pascale", via Mariano Semmola, 80131 Naples, Italy

2 Thyroid Surgery Unit, National Cancer Institute "Fondazione G. Pascale", Naples, Italy

3 Department of Industrial Engineering, University of Naples "Federico II", via Claudio - 21, 80131 Naples, Italy

4 Department of Clinical Medicine and Surgery, University of Naples "Federico II", via Pansini - 5, 80131 Naples, Italy

5 Clinical Cytopathology Service, Institute of Pathology, via A. Franzoni - 45, 6601 Locarno, Switzerland correlation. The correlation study between cytology and histology showed an accuracy of FNC in classic, follicular, and oncocytic PTC variants of $63.5,87.5$, and $87 \%$ respectively. Familiarity with cytological features may allow an early diagnosis of a given PTC variant on FNC samples. This is fundamental in a preoperative evaluation for the best surgical approach and subsequent treatment.

Keywords Papillary thyroid carcinoma $\cdot$ Fine needle cytology $\cdot$ Cytological variants $\cdot$ Cytohistological correlation

\section{Introduction}

Among all thyroid carcinomas, papillary thyroid carcinoma (PTC) is the most common malignancy, accounting for approximately $80 \%$ [1], with a female preponderance.

Fine needle cytology (FNC) has been universally accepted as a useful preoperative procedure for thyroid nodules [2-4]. It is highly specific in diagnosing papillary carcinoma, with an estimated accuracy of 94\% [5-7]. Histologically, several variants of PTC have been described, taking into account definite characteristics, such as size (papillary microcarcinoma); borders (encapsulated); architecture (papillary, follicular, macrofollicular, cribriform-morular, solid, micropapillary); cell type (tall cell, columnar, oncocytic, clear cell, hobnail); stromal aspects (papillary carcinoma with fasciitis-like stroma); additional malignant elements (papillary carcinoma with focal insular component, papillary carcinoma with spindle and giant cell carcinoma, papillary carcinoma with squamous cell carcinoma, papillary carcinoma with mucoepidermoid carcinoma), and a combination of the previous features (diffuse sclerosing, diffuse follicular) [8]. The indication of PTC variant is mainly based on histopathological diagnosis, because the possibility to identify the different variants on FNC seems 
rather low and it depends on the experience of the cytopathologist.

Retrospective studies have been performed on the accuracy of FNC to identify PTC variants [2, 9, 10], but many reports describe the cytomorphology of either a single [11-19] or two cases of variants of PTC [20-22]. To our knowledge, no prospective studies on accuracy of FNC in thyroid malignant neoplasm of a large series have ever been carried out. In the present study, we report the cytological features defining which of them have more diagnostic weight and frequency in the prediction of the different variants of PTC on FNC, through univariate and multivariate statistical analyses. The prediction of a specific PTC variant was then confirmed or refused by cytohistological comparison. While some variants do not pose diagnostic problems, some others can be extremely difficult, such as the uncommon ones (tall cell, diffuse sclerosing, cystic, Warthin-like and cribriform-morular) that are sometimes associated with clinical conditions and may have an adverse prognosis. Therefore, familiarity with cytological features may allow an early diagnosis of a given PTC variant, which is of crucial importance in the preoperative evaluation for the best surgical approach and subsequent treatment.

\section{Materials and Methods}

A prospective study on 128 patients (102 women and 26 men) with PTC diagnosed at the National Cancer Institute "Fondazione G. Pascale" of Naples, Italy, from 2008 to 2015, has been carried out. During this time, 3958 thyroid FNCs have been performed and diagnosed following SIAPEC-IAT 2011 guidelines, amended in 2014. The cases have been classified as follows: 72 TIR 1 (2\%), 3246 TIR 2 (82\%), 426 TIR 3 (11\%), 98 TIR 4 (2\%), and 116 TIR $5(3 \%)$. Only FNC thyroid reports with indication of the possible variant of PTC, previous to surgery and histopathological diagnosis, have been selected. In detail, the studied cases were 106 TIR 5 and 22 TIR 4. The median patients' age was 40 (1182 years old), with a 1:4.7 male to female ratio.

FNC samples of thyroid nodules (ranging from 0.4 to $6 \mathrm{~cm}$ in diameter) were obtained under ultrasound guidance by using 23-25-G needles, without suction, with a number of passages ranging from 1 to 5 . The number of passages has been acquired either from its statement in the report working sheet or derived from the number of slides obtained (1 passage $=3$ slides). The smears were either air-dried and stained with Diff Quik ${ }^{\mathrm{TM}}$ or wet-fixed in $95 \%$ ethanol and stained with Papanicolaou (Pap).

After the prospective cytological diagnosis, the smears were blindly reviewed by two cytopathologists (FF and LS) and a frequency score $(0,1,2,3)$ of the different features for each variant was created (Table 1 ). The cytological parameters were divided into three groups: architectural (cellularity, microacinar structures, syncytial clusters, monolayered sheets, papillary fronds, branching sheets, solid cell balls, hollow balls); nucleo-cytoplasmic characteristics (nuclear grooves, intranuclear cytoplasmic inclusions (INCI), nucleoli, anisonucleosis, irregular nuclear membrane, nucleomegaly, fine powdery chromatin, granular cytoplasm, anisocytosis, abundant eosinophilic cytoplasm, hobnail cells, septate cytoplasmic vacuoles, large vacuoles); and background features (filamentous dense colloid, nonfilamentous dense colloid, histiocytes, multinucleated giant cells, dystrophic calcifications/ psammoma bodies, squamous cells, lymphocytes). The histopathological criteria used for the diagnosis of CPTC and its variants were derived from the Atlas "Tumors of the thyroid and parathyroid glands" [23].

Based on diagnostic criteria for non-invasive follicular thyroid neoplasm with papillary-like nuclear features (NIFTP) suggested by Nikiforov et al. [24], the capsules of histological samples of follicular variant of papillary thyroid carcinoma (FVPTC) were completely examined in multiple sections, which led to the final diagnosis of NIFTP.

\section{Cytological Criteria to Define the Different Subtypes of PTC}

For the cytodiagnosis of different PTC variants, the used criteria are reported in Table 1. Cases diagnosed as cPTC included frequent papillary clusters and/or branching sheets (which are the equivalent bidimensional feature of papillae) and monolayered sheets; nuclear grooves, fine powdery chromatin, small intranuclear inclusions, anisonucleosis, and irregular nuclear membrane; and dense filamentous colloid, single squamoid cells, and multinucleated giant cells were also seen rather frequently in the background.

FVPTC presented a predominance of microacinar structures and infrequent or absent papillary fronds; the nuclei showed rare nuclear grooves and more frequent micronucleoli; intranuclear cytoplasmic inclusions were more frequent and comparatively larger than in CPCT; and nonfilamentous dense or watery colloid prevailed in the background.

The oncocytic variant of PCT showed a pure population, or more than $30 \%$, of large tumor cells with abundant eosinophilic and granular cytoplasms on PAP staining or violet and granular cytoplasms on DQ stained smears; frequent multiple intranuclear inclusions in the same nucleus and frequent grooves were visible; the background was characterized by poor colloid with frequent accessory findings of chronic lymphocytic thyroiditis.

Uncommon variants of PTC: in our series, tall cell and cystic variants were often recognized on FNC. Tall cell variant cases showed elongated tumor cells, which were twice as tall as their width, with overlapping and stratification of nuclei, 
Table 1 For each cytological feature, the number of cases out of the total number of cases of each PTC variant, the relative percentages, and the most represented cytological score (in brackets) are reported. The last column of the table reports the univariate analysis of the cytological parameters ( $p$ value) carried out on the whole population

\begin{tabular}{|c|c|c|c|c|}
\hline \multirow[t]{2}{*}{ Cytological features } & \multicolumn{3}{|c|}{ No/tot cases—\%-(score) } & \multirow[t]{2}{*}{$p$ value } \\
\hline & Classic & Follicular & Oncocytic & \\
\hline \multicolumn{5}{|c|}{ ARCHITECTURE } \\
\hline Cellularity & $31 / 44-70 \%-(3)$ & $27 / 45-60 \%-(3)$ & $22 / 27-81 \%-(3)$ & \\
\hline Microacinar structures & $38 / 44-86 \%-(0)$ & $21 / 45-47 \%-(2)$ & $24 / 27-89 \%-(0)$ & $<0.001$ \\
\hline Syncytial clusters & $24 / 44-54 \%-(0)$ & $20 / 45-44 \%-(0)$ & $14 / 27-52 \%-(1)$ & \\
\hline Monolayered sheets & $25 / 44-57 \%-(2)$ & $20 / 45-44 \%-(2)$ & $15 / 27-56 \%-(2)$ & \\
\hline Papillary fronds & $23 / 44-52 \%-(2)$ & $14 / 45-31 \%-(0)$ & $18 / 27-67 \%-(2)$ & $<0.001$ \\
\hline Branching sheets & $22 / 44-50 \%-(3)$ & $17 / 45-38 \%-(0)$ & $11 / 27-41 \%-(3)$ & 0.001 \\
\hline Solid cell balls & $42 / 44-95 \%-(0)$ & $43 / 45-95 \%-(0)$ & $27 / 27-100 \%-(0)$ & \\
\hline Hollow balls & $44 / 44-100 \%-(0)$ & $45 / 45-100 \%-(0)$ & $27 / 27-100 \%-(0)$ & \\
\hline \multicolumn{5}{|c|}{ NUCLEO-CYTOPLASMIC FEATURES } \\
\hline Nuclear grooves & 26/44-59\%-(1) & $21 / 45-47 \%-(3)$ & $13 / 27-48 \%-(3)$ & $<0.001$ \\
\hline $\begin{array}{l}\text { Intranuclear cytoplasmic inclusions } \\
\text { (INCI) }\end{array}$ & $20 / 44-45 \%-(2)$ & $18 / 45-40 \%-(2)$ & $14 / 27-52 \%-(3)$ & 0.001 \\
\hline Nucleoli & 41/44-93\%-(0) & 29/45-64\%-(0) & $17 / 27-63 \%-(1)$ & 0.01 \\
\hline Anisonucleosis & $19 / 44-43 \%-(1)$ & $21 / 45-47 \%-(2)$ & $20 / 27-74 \%-(2)$ & $<0.001$ \\
\hline Irregular nuclear membrane & $23 / 44-52 \%-(1)$ & $35 / 45-78 \%-(1)$ & $16 / 27-59 \%-(1)$ & 0.03 \\
\hline Nucleomegaly & $31 / 44-70 \%-(0)$ & $29 / 45-64 \%-(0)$ & $15 / 27-56 \%-(1)$ & 0.003 \\
\hline Fine powdery chromatin & $34 / 44-77 \%-(0)$ & $25 / 45-55 \%-(1)$ & $18 / 27-67 \%-(1)$ & 0.01 \\
\hline Granular cytoplasm & $44 / 44-100 \%-(0)$ & $45 / 45-100 \%-(0)$ & $15 / 27-55 \%-(0)$ & 0.05 \\
\hline Anisocytosis & $21 / 44-48 \%-(0)$ & $25 / 45-55 \%-(0)$ & $22 / 27-81 \%-(2)$ & $<0.001$ \\
\hline Abundant eosinophilic cytoplasm & $34 / 44-77 \%-(0)$ & $43 / 45-95 \%-(0)$ & $17 / 27-63 \%-(2)$ & $<0.001$ \\
\hline Hobnail cells & $44 / 44-100 \%-(0)$ & $45 / 45-100 \%-(0)$ & $25 / 27-93 \%-(0)$ & \\
\hline Septate cytoplasmic vacuoles & $43 / 44-98 \%-(0)$ & $44 / 45-98 \%-(0)$ & $26 / 27-96 \%-(0)$ & \\
\hline Large vacuoles & $44 / 44-100 \%-(0)$ & $45 / 45-100 \%-(0)$ & $27 / 27-100 \%-(0)$ & \\
\hline \multicolumn{5}{|c|}{ BACKGROUND FEATURES } \\
\hline Filamentous dense colloid & $37 / 44-84 \%-(0)$ & $41 / 45-91 \%-(0)$ & $21 / 27-78 \%-(0)$ & \\
\hline Nonfilamentous dense colloid & $25 / 44-57 \%-(0)$ & $26 / 45-58 \%-(0)$ & $16 / 27-59 \%-(0)$ & \\
\hline Histiocytes & $15 / 44-34 \%-(1)$ & $25 / 45-55 \%-(0)$ & $10 / 27-37 \%-(0)$ & \\
\hline Multinucleated giant cells & $17 / 44-39 \%-(2)$ & $21 / 45-47 \%-(0)$ & $15 / 27-55 \%-(2)$ & \\
\hline Dystrophic calcifications/ & $16 / 44-36 \%-(2 / 0)$ & $22 / 45-49 \%-(0 / 0)$ & $13 / 2-48 \%-(0 / 0)$ & 0.01 \\
\hline \multicolumn{5}{|l|}{ Psammoma bodies } \\
\hline Squamous cells & $12 / 44-36 \%-(2)$ & $33 / 45-73 \%-(0)$ & $17 / 27-63 \%-(0)$ & $<0.001$ \\
\hline Lymphocytes & $43 / 44-98 \%-(0)$ & $40 / 45-89 \%-(0)$ & $20 / 27-74 \%-(0)$ & \\
\hline
\end{tabular}

abundant eosinophilic cytoplasm, and nuclear features of PTC. The tall cells represented $>50 \%$ of the papillary carcinoma component. The cystic variant presented thin watery colloid containing rare papillae with clear nuclei and abundant cystic background. Although literature suggests some cytological criteria to identify the diffuse sclerosing variant of PTC on FNC (abundant lymphocytic infiltrate, metaplastic squamous cells in addition to typical features of PTC and the presence of many psammoma bodies), this variant has always been misdiagnosed in our series. The cases histologically diagnosed as a Warthin-like variant were cytologically composed only by oncocytic-type neoplastic cells and could not be cytologically differentiated by the oncocytic variants of PTC [25].

\section{Score and Statistical Analysis}

According to previous similar retrospective studies [11, 12, $15]$, features were graded as absent (score 0 ), occasional (score 1; 1-29\%), frequently seen (score 2; 30-49\%), and prominent finding (score $3 ; 50-100 \%$ ). To obtain a reproducible score for the nucleo-cytoplasmic parameters, 10 random visual fields were evaluated at high magnification $(\times 400)$ in which the frequency of each of the criteria was counted. The final score resulted from their mean. The scores for the architectural and background parameters were calculated in the same way but at a lower magnification $(\times 100)$.

The statistical analysis was performed with the SPSS package for Windows version 10 (Cary, NC, USA). Data were 

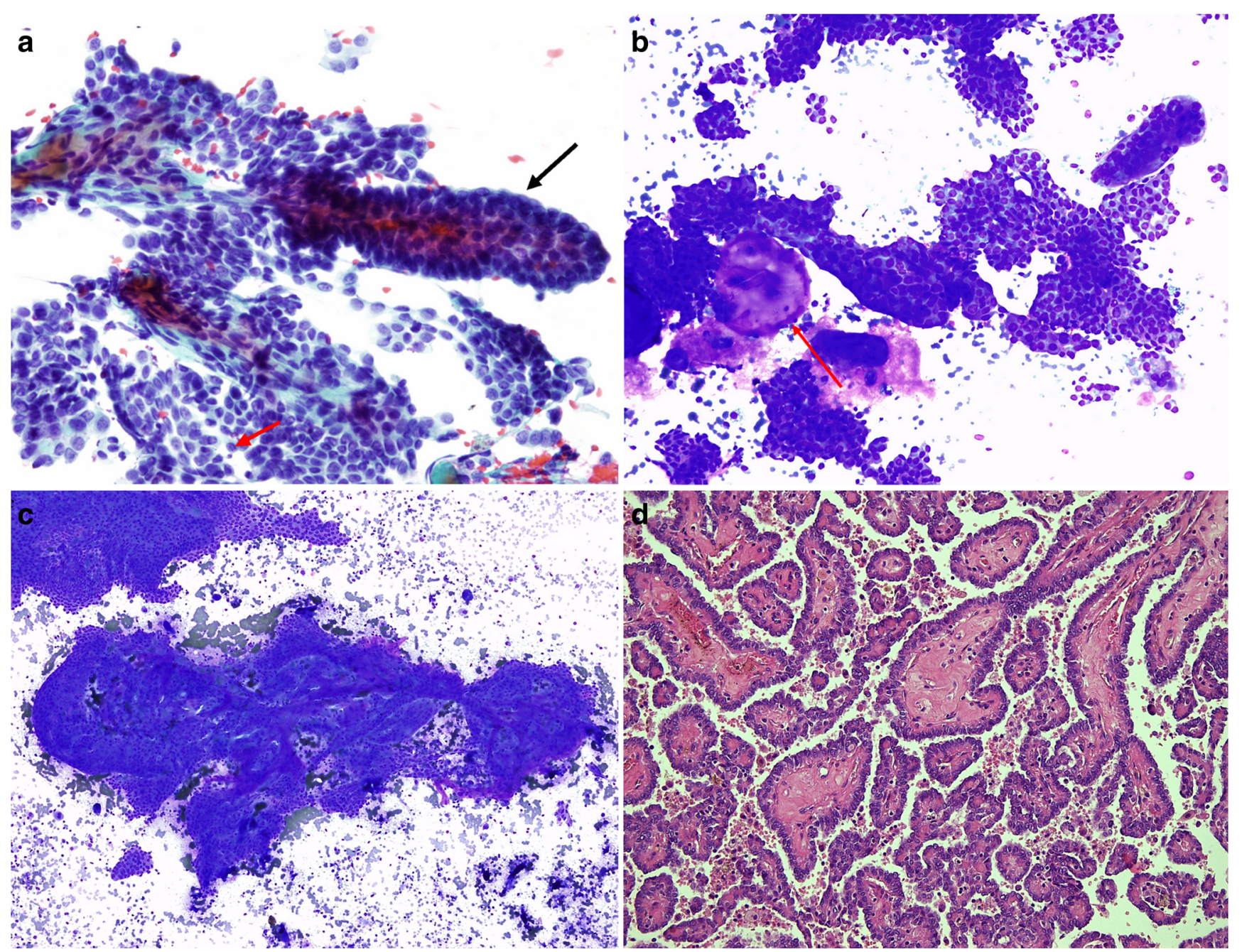

Fig. 1 a-d FNC sample. PTC, classic variant. a A well-preserved papillary structure with a vascular core (black arrow) and nuclear features of PTC (nuclear grooves) (red arrow) (Pap, $\times 60$, original magnification). b At lower magnification, marked branching phenomena can be appreciated in the cell population, as well as the presence of dense globules of colloid substance (red arrow) (DQ, $\times 40$, original magnification). $\mathbf{c}$ Lowpower magnification showing branching sheets of thyreocytes with nuclear features of PTC, centered by a fibrovascular core (DQ, 20×, original magnification). d The corresponding histological sample confirmed the cytological diagnosis $(\mathrm{H} \& \mathrm{E}, \times 20$, original magnification) expressed as mean \pm SEM (standard error of the mean). A univariate analysis was performed by the chi-square test with Yates correction and Fisher exact test as appropriate. Multiple regression analysis was carried out among the variables correlated at the univariate analysis. The $p$ values were given for these analyses. The significance was set at $5 \%$.

\section{Results}

\section{Cytological Findings}

As previously outlined, we used the various cytopathological features in a prospective modality to verify whether we could predict the probability of a given variant of PTC. The revision and re-elaboration of these data led to a frequency analysis of the cytopathological criteria (Table 1). The table also reports the univariate analysis of the cytological parameters ( $p$ value) carried out on the whole population, which will be discussed later on. Among the architectural features, the presence of monolayered sheets, papillary fronds, and branching sheets resulted as the most frequently represented in the cPTC (with a 2-3 score), having been respectively identified in 57, 52, and $50 \%$ of cases. Among the nucleo-cytoplasmic features, INCI were moderately (score 2) expressed in $45 \%$ of cases, while nuclear grooves, anisonucleosis, and irregular nuclear membranes were less prominent (score 1) in respectively 59, 43, and $52 \%$ of cases. The most frequent background features in cPTC were multinucleated giant cells, the presence of dystrophic calcifications, or psammoma bodies and "squamoid" (tall- 


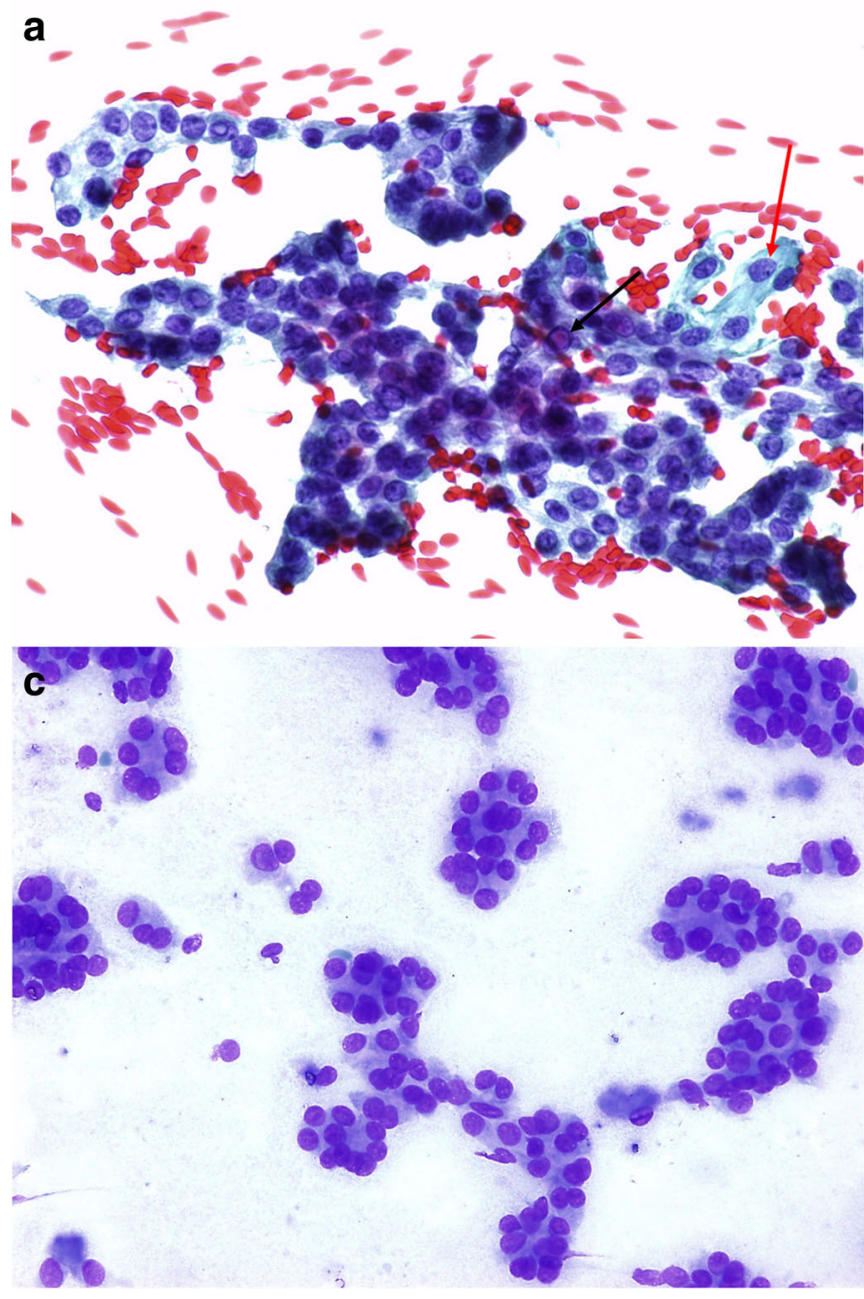

Fig. 2 a-d FNC sample. FVPTC. a Thyreocyte sheets with only slight branching phenomena: the nuclei are vesicular, with micronucleoli (red arrow) and nuclear grooves (black arrow). An occasional intranuclear cytoplasmic inclusion can be seen (DQ, $\times 60$, original magnification). $\mathbf{b}$ Monolayered cellular sheets with nuclear features of PTC, forming b

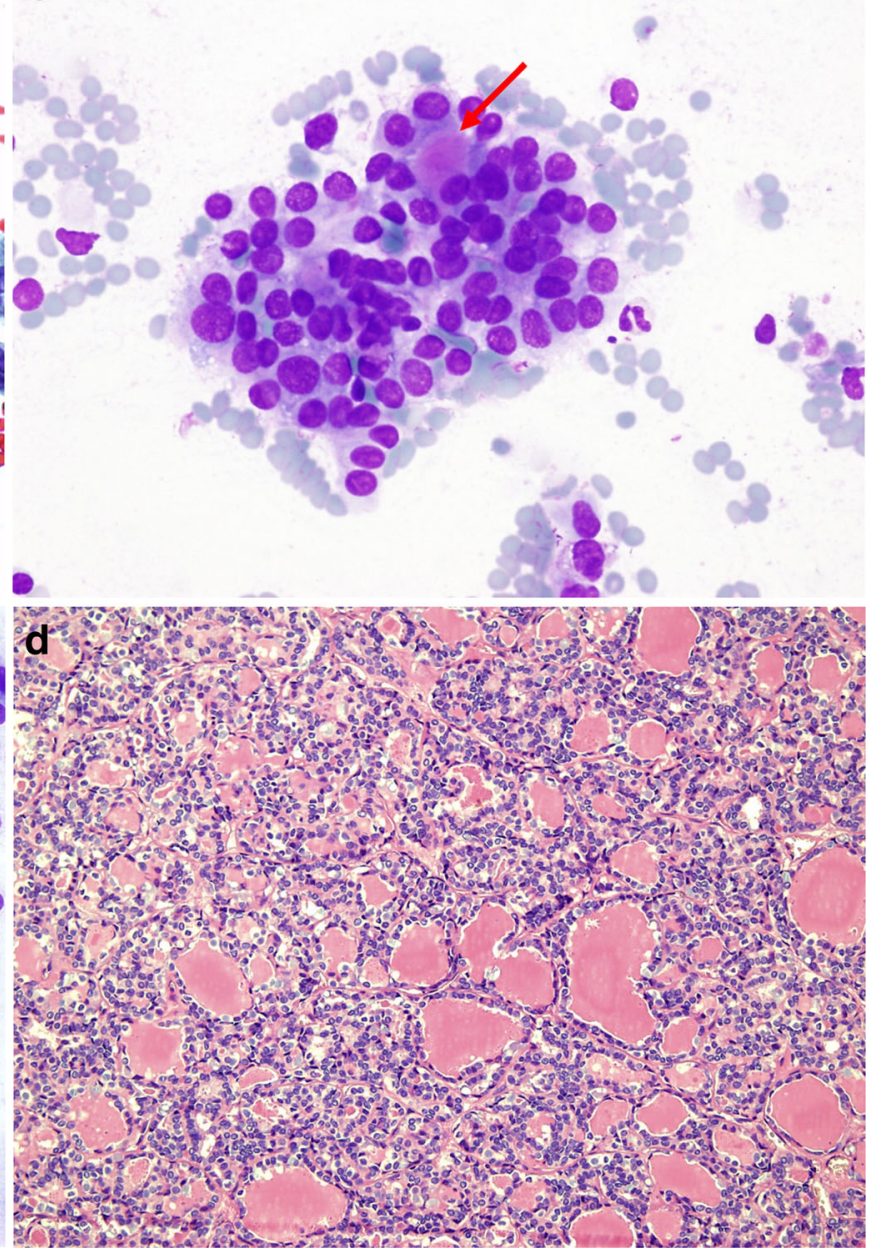

follicular or syncytial structures containing dense colloid (red arrow) (DQ, $\times 60$, original magnification). c Repetitive microacinar structures (DQ, $\times 40$, original magnification). d Corresponding histological sample, confirming the cytological diagnosis $(\mathrm{H} \& \mathrm{E}, \times 20$, original magnification) like) cells, all of them identified at moderate level of expression (score 2) in $36 \%$ of cases. Figure 1 shows a case of cPTC.

As the FVPTC is concerned, we did not find any significant differences in the cytological presentation of its encapsulated (NIFTP) and nonencapsulated (invasive) types. In both forms, microacinar structures and monolayered sheets were the most frequent architectural features, which were observed with a moderate expression (score 2) and found in 47 and $44 \%$ of cases, respectively. Among the nucleo-cytoplasmic features, the most frequent parameters were nuclear grooves, INCI, and anisonucleosis, which were present in 47,40 , and $47 \%$ of cases (score 2-3), respectively. Irregular nuclear membrane and fine powdery chromatin were rather frequent but with low intensity (score 1) and found in 78 and 55\% of cases.

No background parameter was found to be significant in this variant. Figure 2 shows a case of nonencapsulated
FVPTC: the cell population is mostly organized in the form of repetitive microacinar structures with vesicular nuclei, micronucleoli, and nuclear grooves. As it concerns the oncocytic variant of PTC, this has a unique cytological presentation, showing a pure population of oncocytic cells with nuclear features of PTC. Anyway, its most frequent architectural features were represented by monolayered sheets, papillary fronds, and branching sheets (score 2-3), being found in 56,67 , and $41 \%$, respectively, of cases. The most frequent nucleo-cytoplasmic features were represented by nuclear grooves, INCI, anisonucleosis, and the presence of abundant eosinophilic cytoplasm, which were found in $48,52,74$, and $63 \%$, respectively, of cases. Irregular nuclear membrane, fine powdery chromatin, and nucleomegaly were infrequent (score 1). Among the background features, multinucleated giant cells were present in $55.5 \%$ of cases (score 2). 

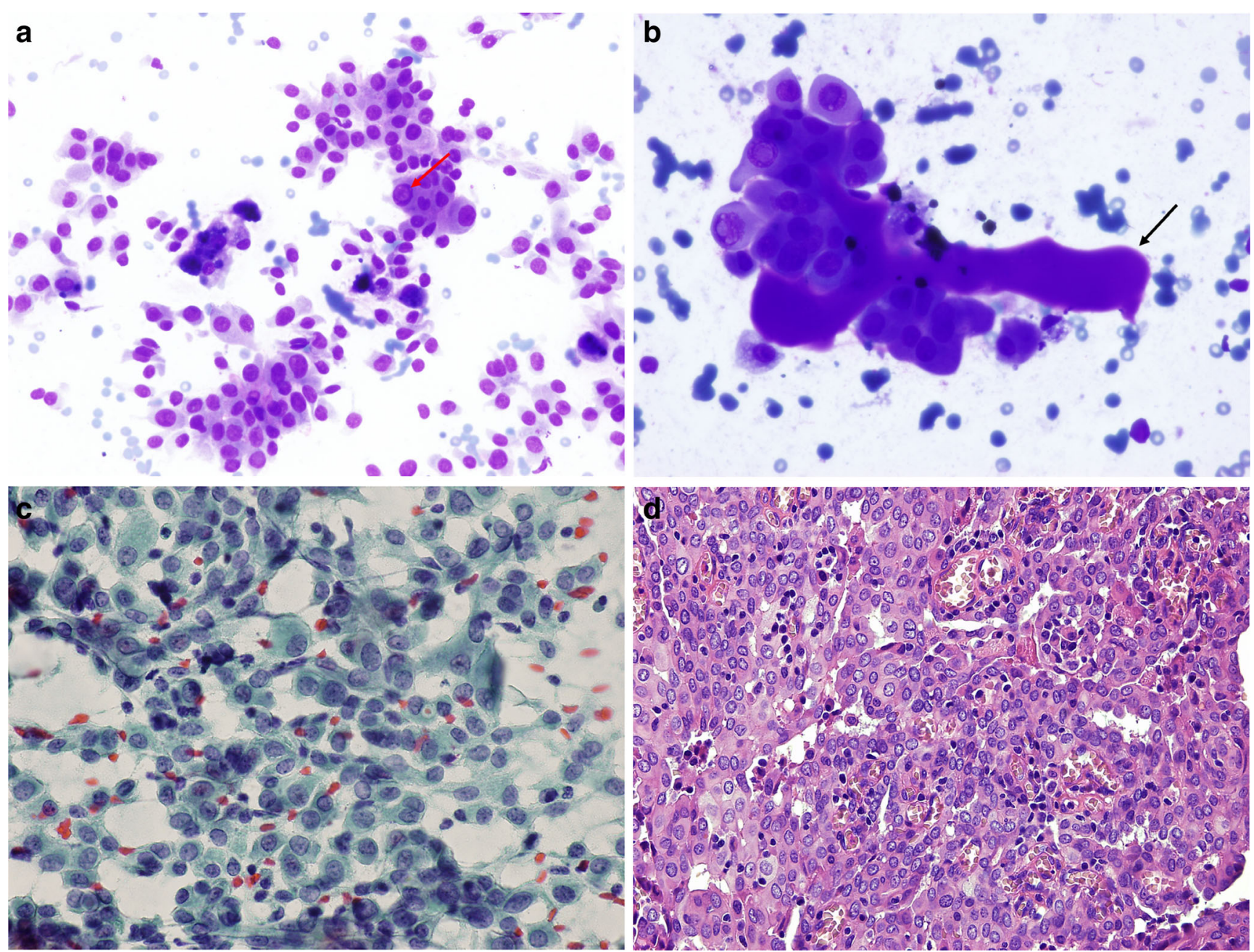

Fig. 3 a-d FNC sample. PTC, oncocytic variant. a Neoplastic epithelial cells with grey to violet granular cytoplasms. The shape of the cytoplasms varies from cylindrical to polygonal. Nuclei are vesicular, with frequent intranuclear cytoplasmic inclusions (black arrow) (DQ, $\times 40$, original magnification). b Notice the presence of dense, almost "squamoid"

Figure 3 shows a case of oncocytic variant of PTC with the corresponding histopathological picture.

Uncommon variants of PTC are difficult to recognize on FNA samples, also in our experience, since few cases were correctly identified prospectively as such. Two cases of uncommon variants are reported below: Fig. 4 shows a case of tall cell variant of PTC along with its histopathological image. This cytological presentation is highly predictive of this variant. Figure 5 shows a case of diffuse sclerosing variant of PTC. This case was cytologically diagnosed as a classic-type PTC within a context of lymphocytic thyroiditis. As it can be observed in the cytological images, although the cytopathological criteria were sufficient for a generic diagnosis of classic PTC, there were no hints to the possibility of a diffuse sclerosing variant. cytoplasms; dense, chewing gum-type colloid; and intranuclear inclusions (red arrow) (DQ, $\times 60$, original magnification). c Abundant and granular cytoplasms with vesicular nuclei and eccentric nucleoli (Pap, $\times 60$, original magnification). d The corresponding histological sample confirmed the cytological diagnosis $(\mathrm{H} \& \mathrm{E}, \times 40$, original magnification)

\section{Cytohistological Correlation}

The preoperative cytological diagnoses of the 128 patients with PTC were 63 PTC classic variant, 32 PTC follicular variant (FVPTC), 15 PTC oncocytic variant, and 18 PTC uncommon variants (tall cell, diffuse sclerosing, cystic, Warthin-like). On histopathologic examination, 44 classic; 45 follicular (of which 7 were NIFTP, 2 cases cytologically diagnosed as TIR 4, and 5 cases as TIR 5); 27 oncocytic; and 12 uncommon variants (tall cell, diffuse sclerosing, cystic, Warthin-like, and cribriform-morular) were diagnosed.

The cytohistological correlation of this series is reported in Table 2. Agreement was achieved in 40/63 cases of cPTC (63.5\%). The remaining 23 cases cytologically identified as classic were histologically redistributed as follows: 12 


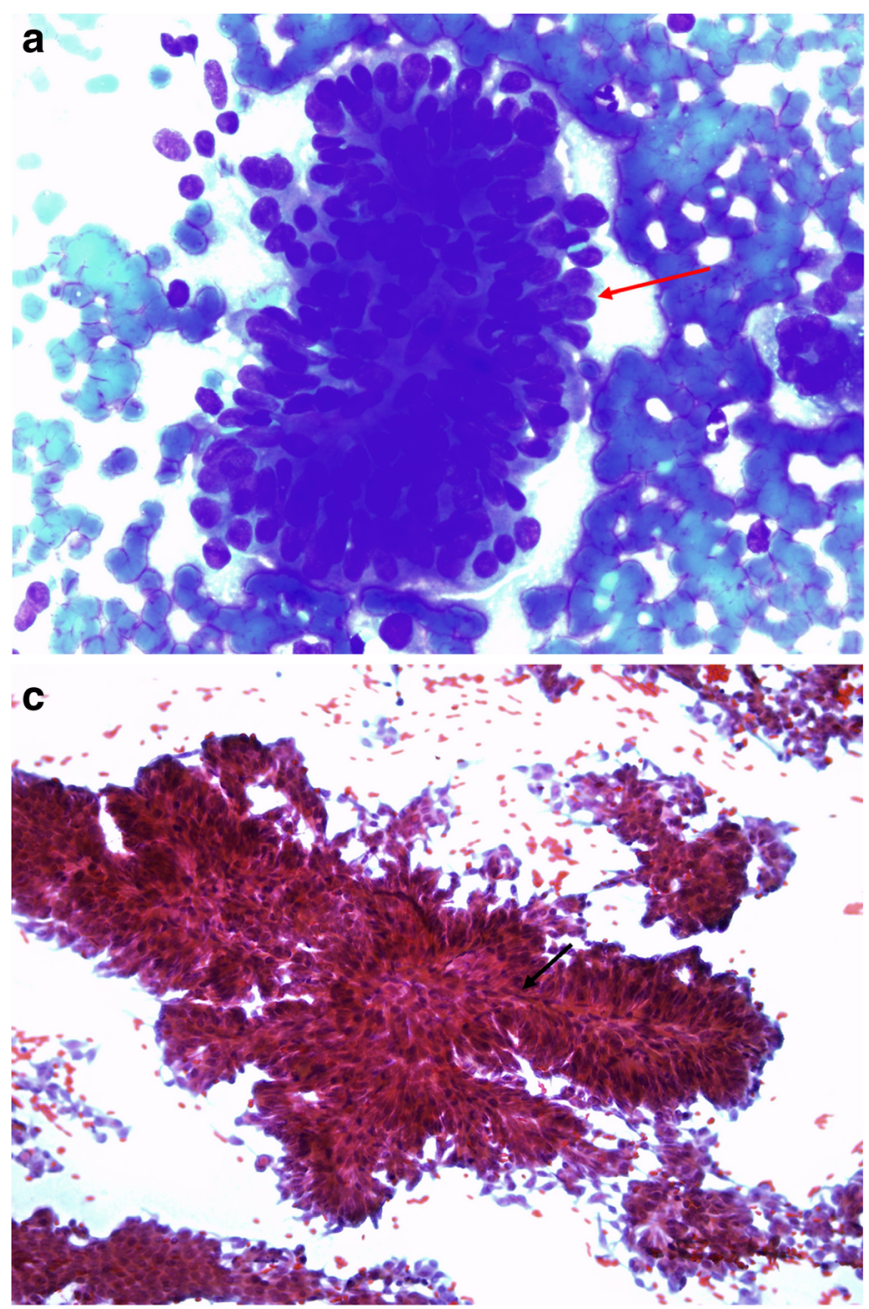

Fig. 4 a-d FNC sample. Tall cell papillary carcinoma. a Smears show papillary fragments of atypical columnar-type epithelium with nuclear palisading. Some nuclear grooves are also present (red arrow) (DQ, $\times 60$, original magnification). b At high magnification, the neoplastic cells show multi-stratification within the papillary fronds. Nuclei present evident nuclear grooves, and the cytoplasms are granular and orangiophilic (Pap, $\times 60$, original magnification). c At low magnification, well-

FVPTC, 9 oncocytic, and 2 uncommon variants (diffuse sclerosing and cribriform-morular). Of the 32 cases cytologically identified as FVPTC, 28 were in agreement with histology with an accuracy of $87.5 \%$. In the remaining cases, histology showed three classic and one oncocytic variants. Of the 15 cases of PTC oncocytic variant, 13 were in agreement with histology, with an accuracy of $87 \%$; in the remaining cases, histology showed one classic and one Warthin-like variant. Of the 18 cases of uncommon variants, only in $6 / 18$ cases did cytopathology precisely identify the histological subtype (2 tall cell and 4 cystic variants). Sensitivity, specificity, positive predictive value (PPV), and negative predictive value (NPV) were calculated for each variant (except for the uncommon ones) and reported in Table 3.

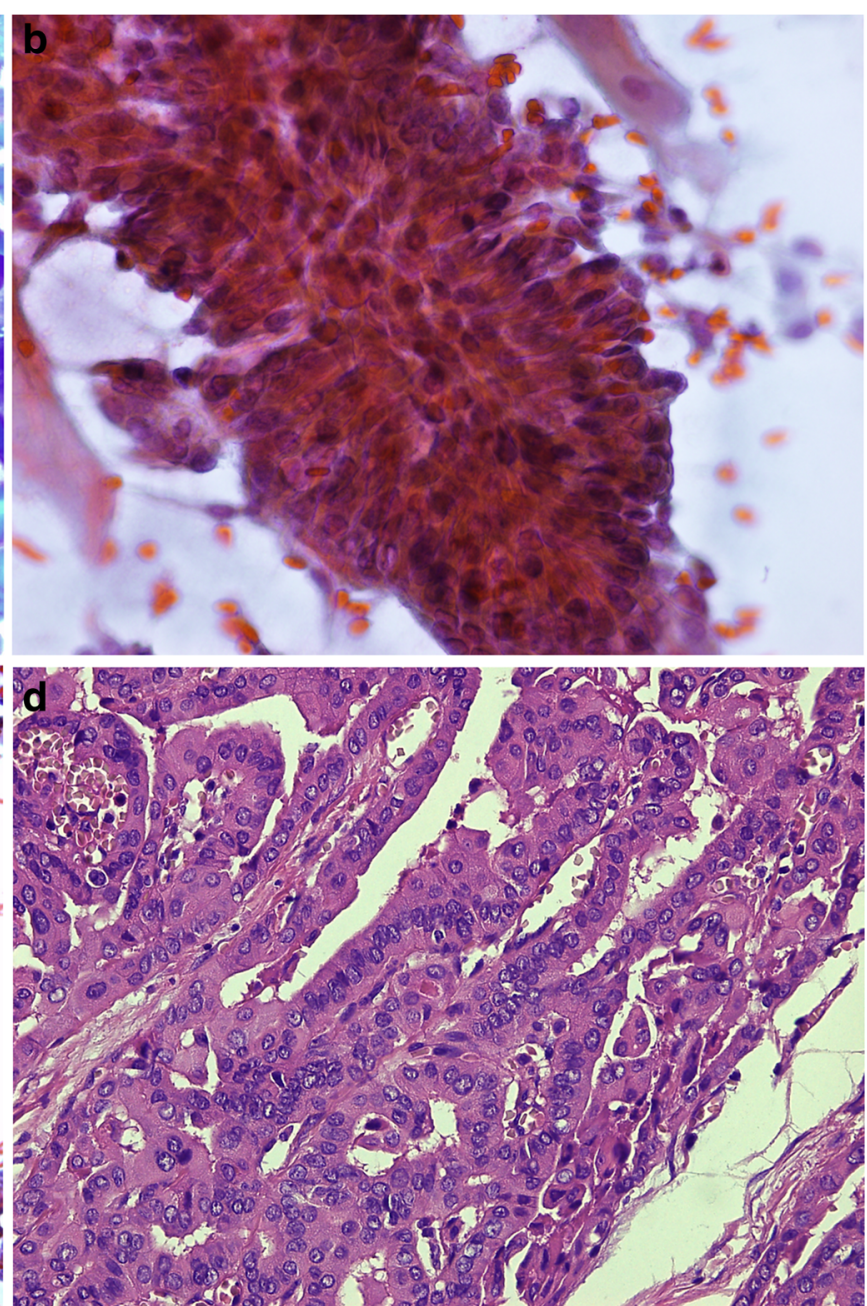

organized papillary fragments of columnar-type cells can be observed. The fragments show a vascular core (black arrow), and the atypical cells present nuclear palisading and a granular, orangiophilic cytoplasm (Pap, $\times 20$, original magnification). d Corresponding histological sample, confirming the cytological diagnosis. Notice the presence of oncocytelike cytoplasms in the neoplasm ( $\mathrm{H} \& \mathrm{E}, \times 40$, original magnification)

\section{Statistical Evaluation of the Cytological Parameters Predictive of a Specific Variant in the Whole Series}

The results of the univariate analysis of the cytological parameters ( $p$ value) are reported in Table 1. Only the cytological features with $p$ value $\leq 0.001$ have been taken into account. Therefore, a moderate-high expression (score 2-3) of papillary fronds and branching sheets, a low-moderate expression of nucleo-cytoplasmic features (nuclear grooves, INCI, and anisonucleosis) (score 1-2), and the presence of squamoid cells in the background prospectively predict PTC classic variant. FVPTC shows a moderate expression (score 2) of microacinar structures and atypical nucleo-cytoplasmic features (grooves, INCI, and anisonucleosis) more frequent 

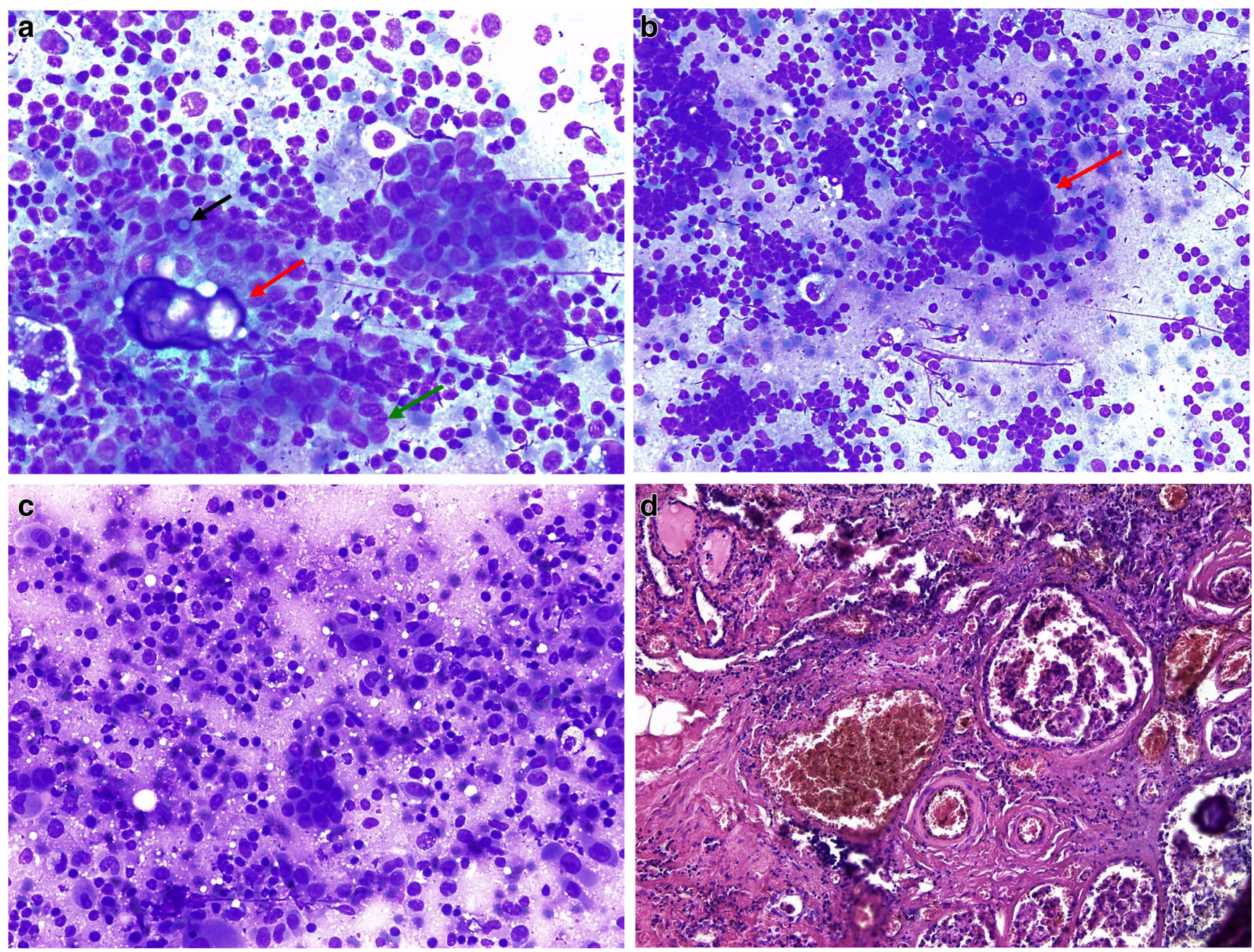

Fig. 5 a-d FNC sample. Diffuse sclerosing-type PTC misdiagnosed as classic variant PTC. a A further field shows blunt papillaroid clusters and loose groups of neoplastic cells with nuclear criteria (intranuclear inclusions (black arrow) and nuclear grooves (green arrow)). The background shows psammoma bodies (red arrow), a few degenerated neoplastic cells, and many lymphoid cells (DQ, $\times 60$, original magnification). b Lowpower magnification shows a neoplastic "cell ball" (red arrow) and few solid trabecular groups of neoplastic thyreocytes with poorly preserved

(score 2-3) than in cPTC. The oncocytic variant shows a moderate expression of papillary fronds (score 2); atypical nucleo-cytoplasmic features (grooves, INCI, anisonucleosis, anisocytosis, and abundant eosinophilic cytoplasm) are even more pronounced (score 2-3) than in FVPTC.

Due to the exiguous number of cases, the uncommon variants have not been considered in the statistical analysis, because of the bias that could be derived.

\section{Discussion}

FNC has become the most popular diagnostic procedure for investigation of thyroid nodules in the last decade [2]. FNC of thyroid is reported to have a sensitivity ranging from 65 to

cytoplasms. In the background, some histiocytes and lymphocytes can also be seen (DQ, $\times 40$, original magnification). $\mathbf{c}$ This microscopic field shows a mainly dispersed cell pattern, with some well-preserved neoplastic cells with nuclear grooves and dense cytoplasms in a background of cell debris and some lymphoid cells (DQ, $\times 40$, original magnification). d Corresponding histological sample show a diffuse sclerosing variant of PTC $(H \& E, \times 20$, original magnification)

$98 \%$, a specificity of 72 to $100 \%$, a positive predictive value of 34 to $100 \%$, and a negative predictive value of 83 to $100 \%$ [6, 7, 9, 19].

A preoperative or intraoperative diagnosis of PTC is important, given that the operative management of PTC and follicular neoplasms differ [26-28]. Although the recognition of variants of PTC may just seem morphologically challenging for the pathologists, some of them may behave in an attenuated or benign fashion (like the NIFTP), while others may act worse than $\mathrm{CPTC}$ and therefore need a more aggressive clinical management [8]. The indication of the PTC variant is based on the histopathological diagnosis, because the possibility to discriminate among the different variants on FNC seems very low and it depends on the experience of the cytopathologist [9]. Specific cytopathological criteria have been 
Table 2 Cytohistological correlation in 128 patients with papillary thyroid carcinoma on fine needle cytology samples

\begin{tabular}{lcccc}
\hline & Cytology & Histology & \multicolumn{2}{c}{ Concordance } \\
\cline { 4 - 5 } & No & No & No & $\%$ \\
\hline Classic & 63 & 44 & 40 & 63.5 \\
FVPTC & 32 & 45 & 28 & 87.5 \\
Oncocytic & 15 & 27 & 13 & 87 \\
Tall cell & 6 & 2 & 2 & 33.3 \\
Diffuse sclerosing & 2 & 4 & 0 & 0 \\
Cystic & 8 & 4 & 4 & 50 \\
Warthin-like & 2 & 1 & 0 & 0 \\
Cribriform-morular & 0 & 1 & 0 & 0 \\
Total & 128 & 128 & 87 & 68 \\
\hline
\end{tabular}

FVPTC follicular variant of papillary thyroid carcinoma (encapsulated and nonencapsulated variants were considered collectively for the purpose of this paper)

extensively described in the literature for each PTC variant. These criteria, however, were identified based either on retrospective examination of small series or single cases [11-22].

In the present study, we reported the results of the accuracy of the cytological analyses on FNC samples in the prospective identification of PTC variants. Our series encompassed classic, follicular, and oncocytic variants of PTC. Gupta et al. [9] carried out a retrospective study on fine needle aspiration smears from 158 histologically proven cases of PTC. The cytological smears were blindly reviewed in an attempt to subclassify them into different variants and to find the discrepancies with the histological diagnoses. Gupta found that a PTC diagnosis on FNC samples could be made in $80.5 \%$ of cases. Also, in the present study, all cases were blindly reviewed by two cytopathologists (FF and SL) and successfully diagnosed, in a preoperative phase, as PTC or suspicious for malignancy. A suggestion on the possible variant was also put forward. A frequency score $(0,1,2,3)$ assigned to selected cytological parameters was then created. Among the cytoarchitectural features, a moderate-high expression (score 2-3) of papillary fronds and branching sheets; a low expression (score 1) of nucleo-cytoplasmic features (nuclear grooves, INCI, and anisonucleosis); and the presence of squamoid cells in the background were predictive of cPTC,

Table 3 Sensibility, specificity, PPV, and NPV for each variant

\begin{tabular}{lllll}
\hline & Sensibility (\%) & Specificity (\%) & PPV (\%) & NPV (\%) \\
\hline Classic & 92 & 78.5 & 66 & 95 \\
FVPTC & 73 & 95 & 92 & 83 \\
Oncocytic & 66 & 98 & 93 & 88 \\
\hline
\end{tabular}

FVPTC follicular variant of papillary thyroid carcinoma, $N P V$ negative predictive value, $P P V$ positive predictive value in agreement with the already established cytopathological criteria $[20,29,30]$. In our series, these nucleo-cytoplasmic characteristics, although thought to be pathognomonic signs of the $\mathrm{CPTC}$, were found to be less prominent than in the other variants.

Although several cytological criteria predictive of the follicular variant are present in literature [2, 7, 8, 31, 32], this diagnosis still remains difficult. In agreement with Fulciniti et al. [11], FVPTC, in our series, shows in almost half of the cases a moderate-high expression (score 2-3) of microacinar structures and atypical nucleo-cytoplasmic features (grooves, INCI, and anisonucleosis), more expressed than in cPTC. In previous studies, other cytological features of this variant were emphasized, such as dense colloid and micro/macronucleoli more than INCI [33, 34]. In the present study, these parameters become less relevant probably due to a higher number of analyzed cases. Due to the recent observation that the NIFTP subclass of FVPTC has an almost invariably benign clinicpathological behavior [35-37], our suggestion is that, when diagnostic criteria point to FVPTC, a comment should be added including NIFTP in the differential diagnosis, also according to Krane et al. [38]. With the concept of the possibility of a NIFTP when facing a follicular-patterned lesion with nuclear features of papillary carcinoma, the choice of adopting a TIR 3B category instead of TIR 4 or TIR 5, like in our series, obtained in a period in which this latter lesion had not been studied enough, may better reflect the relatively indolent prognosis of this lesion as opposed to other variables of papillary carcinoma. As already stated in the "Results" section, no diagnostic cytopathological criteria were found to be useful to differentiate NIFTP from nonencapsulated variants of FVPTC in the current as in other published series [36, 39], with the exception of the recent paper by Ibrahim and $\mathrm{Wu}$ [40].

The oncocytic variant shows a moderate-high (score 2-3) expression of papillary fronds and atypical nucleocytoplasmic features (grooves, INCI, anisonucleosis, anisocytosis, and abundant eosinophilic cytoplasm), more pronounced than in FVPTC. Because of the small number of uncommon variants in our series, it was not possible to assign specific cytomorphological characteristics to each rare variant. In general, cytopathologic criteria in this group are more consistently predictive of the oncocytic variant only because of the relative number of cases of this category as compared to other variants.

The overall cytohistological concordance of the series was $68 \%$. The accuracy of the main variants varied from $63.5 \%$ of cPTC to $87.5 \%$ of FVPTC; the cytological accuracy of the uncommon variants is very low because of their rarity, which does not allow a familiarity with their characteristics. In detail, the diagnosis of cPTC showed a sensitivity of $92 \%$, higher than in the other variants, and NPV of $95 \%$. Specificity and PPV were 78.5 and $66 \%$, respectively. These latter lower figures were due to a high number of "false positives," in which 
the cPTC diagnosed on FNC resulted to be, instead, follicular/ oncocytic variants on the subsequent histological examination. In our series, in agreement with previous studies [20, 41], the diagnosis of FVPTC showed a sensitivity of $73 \%$ and NPV of $83 \%$; specificity and PPV were of 95 and $92 \%$, respectively. These results can be explained by the fact that only four cases were "false positives," in which the diagnosis of FVPTC on FNC resulted to belong to other variants on the subsequent histological examination; 13 "false negative" cases, cytologically diagnosed as classic and cystic variants, were diagnosed as FVPTC on the definitive histological examination. The diagnosis of the oncocytic variant of PTC had a sensitivity of $66 \%$ and NPV of $88 \%$ and a specificity of $98 \%$ and PPV of $93 \%$. In nine cases, this variant was interpreted as classic, probably due to a nonrepresentative sampling which led to a misdiagnosis; three cases were identified as a tall cell variant due to a high number of "tall cell types," and one case was interpreted as Warthin-like, due to a concomitant thyroiditis, which has mimicked the typical associated lymphocytic infiltrate $[42,43]$. In conclusion, the cytological features of the more common variants of PTC (classic, follicular, and oncocytic) are nowadays well described and recognizable.

The diagnosis of NIFTP identifies a category of lesions with benign or attenuated clinical course, and its possibility should be mentioned in the cytological report when a follicular-patterned lesion with nuclear features of papillary carcinoma is observed [38, 39, 44].

At the time of writing, even though the FNA samples of a "relatively large collection" of NIFTP have been re-examined after surgery, no unequivocal cytopathological feature seems to have predictive value in discriminating them for the FVPTC. More studies, instead, have to be carried out on the uncommon variants. It would be desirable to be able to collect many cases for each rare variant (tall cell, diffuse sclerosing, cystic, Warthin-like, cribriform-morular) in order to define the specific cytological characteristics of each one of them.

\section{Compliance with Ethical Standards}

Conflict of Interest The authors declare no conflict of interest regarding the production of this article. The authors have no personal financial or institutional interest in any of the drugs, materials, or devices described in this article.

\section{References}

1. Davis L, Welch HG (2006) Increasing incidence of thyroid cancer in the United State, 1973-2002. JAMA 295:2164-2167.

2. Nguyen GK, Lee MW, Ginsberg J, Wragg T, Bilodeau D (2005) Fine-needle aspiration of the thyroid: an overview. CytoJournal 2: 12

3. Cibas ES, Bibbo M (2011) Thyroid FNA: challenges and opportunities. Acta Cytol 55(6):489-491.
4. Layfield LJ, Cibas ES, Gharib H, Mandel SJ (2009) Thyroid aspiration cytology: current status. CA Cancer J Clin 59(2):99-110.

5. Sinna EA, Ezzat E (2012) Diagnostic accuracy of fine needle aspiration cytology in thyroid lesions. J Egypt Natl Canc Inst 24:63-70.

6. Schiro AJ, Pinchot SN, Chen H, Sippel RS (2010) Clinical efficacy of fine-needle aspiration biopsy of thyroid nodules in males. J Surg Res 159(2):645-650.

7. Lingam RK, Qarib MH, Tolley NS (2013) Evaluating thyroid nodules: predicting and selecting malignant nodules for fine-needle aspiration (FNA) cytology. Insights Imaging 4(5):617-624.

8. Sak SD (2015) Variants of papillary thyroid carcinoma: multiple faces of a familiar tumor. Turk Patoloji Derg 31(1):34- 47.

9. Gupta S, Sodhani P, Jain S, Kumar N (2004) Morphologic spectrum of papillary carcinoma of the thyroid: role of cytology in identifying the variants. Acta Cytol 48(6):795-800.

10. Nair M, Kapila K, Karak AK, Verma K (2001) Papillary carcinoma of the thyroid and its variants: a cytohistological correlation. Diagn Cytopathol 24(3):167-173.

11. Fulciniti F, Benincasa G, Vetrani A, Palombini L (2001) Follicular variant of papillary carcinoma: cytologic findings on FNAB samples-experience with 16 cases. Diagn Cytopathol 25(2):86-93.

12. Manimaran D, Karthikeyan TM, Khan DM, Raman RT (2014) Follicular variant of papillary thyroid carcinoma: cytological indicators of diagnostic value. J Clin Diagn Res 8(3):46-48.

13. Wu HH, Jones JN, Grzybicki DM, Elsheikh TM (2003) Sensitive cytologic criteria for the identification of follicular variant of papillary thyroid carcinoma in fine-needle aspiration biopsy. Diagn Cytopathol 29(5):262-266.

14. Kesmodel SB, Terhune KP, Canter RJ, Mandel SJ, LiVolsi VA et al (2003) The diagnostic dilemma of follicular variant of papillary thyroid carcinoma. Surgery 134(6):1005-1012.

15. Jogai S, Adesina AO, Temmim L, Al-Jassar A, Amir T et al (2004) Follicular variant of papillary thyroid carcinoma - a cytological study. Cytopathol 15(4):212-216.

16. Takagi N, Hirokawa M, Nobuoka Y, Higuchi M, Kuma S et al (2014) Diffuse sclerosing variant of papillary thyroid carcinoma: a study of fine needle aspiration cytology in 20 patients. Cytopathol 25(3):199-204.

17. Lee SH, Jung CK, Bae JS, Jung SL, Choi YJ et al (2014) Liquidbased cytology improves preoperative diagnostic accuracy of the tall cell variant of papillary thyroid carcinoma. Diagn Cytopathol 42(1):11-17.

18. Yang GC, Stern CM, Messina AV (2010) Cystic papillary thyroid carcinoma in fine needle aspiration may represent a subset of the encapsulated variant in WHO classification. Diagn Cytopathol 38(10):721-726.

19. Erșen A, Durak MG, Canda T, Sevınç AI, Saydam S et al (2013) Warthin-like papillary carcinoma of the thyroid: a case series and review of the literature. Turk Patoloji Derg 29(2):150-155.

20. Ozdemir D, Ersoy R, Cuhaci N, Arpaci D, Ersoy EP et al (2011) Classical and follicular variant papillary thyroid carcinoma: comparison of clinical, ultrasonographical, cytological, and histopathological features in 444 patients. Endocr Pathol 22(2):58-65.

21. Solomon A, Gupta PK, LiVolsi VA, Baloch ZW (2002) Distinguishing tall cell variant of papillary thyroid carcinoma from usual variant of papillary thyroid carcinoma in cytologic specimens. Diagn Cytopathol 27(3):143-148.

22. Guan H, Vandenbussche CJ, Erozan YS, Rosenthal DL, Tatsas AD et al (2013) Can the tall cell variant of papillary thyroid carcinoma be distinguished from the conventional type in fine needle aspirates? A cytomorphologic study with assessment of diagnostic accuracy. Acta Cytol 57(5):534-542.

23. Rosai J, De Lellis RA, Carcangiu ML, Frable WJ, Tallini G et al (2014) Tumors of the thyroid and parathyroid glands. AFIP atlas of tumor pathology. Fourth series; fascicle 21. Silver Spring, Maryland: American Registry of Pathology 606 pp. 
24. Nikiforov YE, Seethala RR, Tallini G, Baloch ZW, Basolo F et al (2016) Nomenclature revision for encapsulated follicular variant of papillary thyroid carcinoma: a paradigm shift to reduce overtreatment of indolent tumors. JAMA Oncol 2(8):1023-1029.

25. D'Antonio A, De Chiara A, Santoro M, Chiappetta G, Losito NS (2000) Warthin-like tumour of the thyroid gland: RET/PTC expression indicates it is a variant of papillary carcinoma. Histopathology 36:493-498.

26. Jones MK (2002) Management of papillary and follicular thyroid cancer. J R Soc Med 95(7):325-326.

27. Mazzaferri EL, Kloos RT (2001) Clinical review 128: current approaches to primary therapy for papillary and follicular thyroid cancer. J Clin Endocrinol Metab 86(4):1447-1463.

28. Pacini F, Schlumberger M, Dralle H, Elisei R, Smit JW et al (2006) European consensus for the management of patients with differentiated thyroid carcinoma of the follicular epithelium. Eur $\mathrm{J}$ Endocrinol 154(6):787-803.

29. Renshaw AA (2002) Focal features of papillary carcinoma of the thyroid in fine-needle aspiration material are strongly associated with papillary carcinoma at resection. Am J Clin Pathol 118:208210.

30. Baloch ZW, LiVolsi VA, Asa SL, Rosai J, Merino MJ et al (2008) Diagnostic terminology and morphologic criteria for cytologic diagnosis of thyroid lesions: a synopsis of the National Cancer Institute Thyroid Fine-Needle Aspiration State of the Science Conference. Diagn Cytopathol 36:425-437.

31. Aron M, Mallik A, Verma K (2006) Fine needle aspiration cytology of follicular variant of papillary carcinoma of the thyroid: morphologic pointers to its diagnosis. Acta Cytol 50(6):663-668.

32. Powari M, Dey P, Saikia UN (2003) Fine needle aspiration cytology of follicular variant of papillary carcinoma of thyroid. Cytopathology 14(4):212-215.

33. Zacks JF, de las Morenas A, Beazley RM, O'Brien MJ (1998) Fineneedle aspiration cytology diagnosis of colloid nodule versus follicular variant of papillary carcinoma of the thyroid. Diagn Cytopathol 18(2):87-90.

34. Glant MD, Berger EK, Davey DD (1984) Intranuclear cytoplasmic inclusions in aspirates of follicular neoplasms of the thyroid. A report of two cases. Acta Cytol 28(5):576-580.
35. Gupta S, Ajise O, Dultz L, Wang B, Nonaka D et al (2012) Follicular variant of papillary thyroid cancer: encapsulated, nonencapsulated, and diffuse: distinct biologic and clinical entities. Arch Otolaryngol Head Neck Surg 138:227-233.

36. Thompson LD (2016) Ninety-four cases of encapsulated follicular variant of papillary thyroid carcinoma: a name change to Noninvasive Follicular Thyroid Neoplasm with Papillary-like Nuclear Features would help prevent overtreatment. Mod Pathol 29(7):698-707.

37. Hodak S, Tuttle RM, Maytal G, Nikiforov YE, Randolph G (2016) Changing the cancer diagnosis: the case of follicular variant of papillary thyroid cancer-primum non nocere and NIFTP. Thyroid 26(7):869-871.

38. Krane JF, Alexander EK, Cibas ES, Barletta JA (2016) Coming to terms with NIFTP: a provisional approach for cytologists. Cancer 124(11):767-772.

39. Maletta F, Massa F, Torregrossa L, Duregon E, Casadei GP et al (2016) Cytological features of "noninvasive follicular thyroid neoplasm with papillary-like nuclear features" and their correlation with tumor histology. Hum Pathol 54:134-134.

40. Ibrahim AI, Wu HH (2016) Fine-needle aspiration cytology of noninvasive follicular variant of papillary thyroid carcinoma is cytomorphologically distinct from the invasive counterpart. Am J Clin Pathol 146:373-377.

41. Tielens ET, Sherman SI, Hruban RH, Ladenson PW (1994) Follicular variant of papillary thyroid carcinoma. A clinicopathologic study. Cancer 73(2):424-431.

42. Paker I, Kokenek TD, Yilmazer D, Seker GE, Alper M (2012) Oncocytic variant of papillary thyroid carcinoma with lymphocytic stroma (Warthin-like variant): report of a case with fine needle aspiration cytology and review of the literature. Cytopathology 23(6):408-410.

43. Lee J, Hasteh F (2009) Oncocytic variant of papillary thyroid carcinoma associated with Hashimoto's thyroiditis: a case report and review of the literature. Diagn Cytopathol 37(8):600-606.

44. Baloch ZW, Seethala RR, Faquin WC, Papotti MG, Basolo F et al (2016) Noninvasive follicular thyroid neoplasm with papillary-like nuclear features (NIFTP): a changing paradigm in thyroid surgical pathology and implications for thyroid cytopathology. Cancer Cytopathol 124(9):616-620. 